\title{
REFERENCES
}

Carter S. J. (1979) Invited comments. Fournal of Surgery 4, 93-4.

Gill M. J. et al., (1956) Therapy for recurrency herpetic whitlow. Annals of Internal Medicine 4, 631.

Laskin O. L. (1985) Acyclovir and surpression of frequently recurring herpetic whitlow. Annals of Internal Medicine 102, 494-5.

Louis D. S. \& Silva J. (1979) Herpetic whitlow: herpetic infection of the digits. Fournal of Hand Surgery 4, 90-3.

Schwandt N. W. et al., (1987) Acyclovir and the treatment of herpetic whitlow. Oral Surgery, Oral Medicine E Oral Pathology 64, 255-8.

\section{The hanging head method for the treatment of acute wry neck}

\section{Sir}

The hanging head method is a simple but effective method for treating acute painful wry neck of spontaneous onset. This method appears not to have been described before in the literature.

Patients with wry neck frequently attend accident and emergency departments seeking relief from a distressing but self-limiting condition. Examination reveals unilateral sternomastoid muscle spasm with torticollis and head tilt to the opposite side.

In the absence of a history of preceding trauma X-rays are not necessary. It is, however, essential to exclude a dystonic reaction to phenothiazines or related drugs. In children, a coexisting sore throat may suggest atlanto-axial rotary fixation, which needs radiographic confirmation.

All other patients can be treated satisfactorily by the hanging head method.

A trolley, stretcher or couch with head-down tilt facility is necessary. The patient is explained that this procedure aims to release spasm of the involved neck muscles.

The patient lies supine and a head-down tilt of about $20^{\circ}$ is provided. The head is brought to the edge of the couch and an assistant supports the pelvis to prevent the patient from sliding down. A period of suspension of betwen 5-10 min is necessary. The dependent head provides a weight to allow traction on the neck. Supplemental manual axial traction to the head and neck may be applied but is not usually necessary. The procedure is terminated if the patient feels unwell in this position.

At the end of the procedure a pain-free patient with a straight neck is obtained. No subsequent immobilization of the neck is necessary, nor are analgesics provided. The author has not encountered any recurrences with this method.

During the period 1 January to 1 June 1988, 23 patients with acute wry neck attended accident and emergency departments in Slough and Ascot. Of these, 10 were submitted to this procedure. None had any recurrent or persistent symptoms. Of the other 13, 4 returned within $24 \mathrm{~h}$ with persistent symptoms. Although these numbers are small, patient satisfaction with this method was universal and the immediate relief of symptoms highly evident to both patient and operator.

\author{
A. BANERJEE \\ Accident \& Emergency Department, \\ General Hospital, \\ Moat Road, \\ Walsall, England
}

